\title{
The atmospheric impact of uncertainties in recent Arctic Sea ice reconstructions
}

\section{Article}

Published Version

Singarayer, J.S., Valdes, P.J. and Bamber, J.L. (2005) The atmospheric impact of uncertainties in recent Arctic Sea ice reconstructions. Journal of Climate, 18 (19). pp. 3996-4012. ISSN 1520-0442 doi: https://doi.org/10.1175/JCLI3490.1 Available at https://centaur.reading.ac.uk/34504/

It is advisable to refer to the publisher's version if you intend to cite from the work. See Guidance on citing.

To link to this article DOI: http://dx.doi.org/10.1175/JCLI3490.1

Publisher: American Meteorological Society

All outputs in CentAUR are protected by Intellectual Property Rights law, including copyright law. Copyright and IPR is retained by the creators or other copyright holders. Terms and conditions for use of this material are defined in the End User Agreement.

\section{www.reading.ac.uk/centaur}

\section{CentAUR}

Central Archive at the University of Reading

Reading's research outputs online 


\title{
The Atmospheric Impact of Uncertainties in Recent Arctic Sea Ice Reconstructions
}

\author{
J. S. Singarayer, P. J. VAldes, And J. L. BAmber \\ Department of Geographical Sciences, Bristol University, Bristol, United Kingdom
}

(Manuscript received 17 June 2004, in final form 4 March 2005)

\begin{abstract}
There are significant discrepancies between observational datasets of Arctic sea ice concentrations covering the last three decades, which result in differences of over $20 \%$ in Arctic summer sea ice extent/area and $5 \%-10 \%$ in winter. Previous modeling studies have shown that idealized sea ice anomalies have the potential for making a substantial impact on climate. In this paper, this theory is further developed by performing a set of simulations using the third Hadley Centre Coupled Atmospheric Model (HadAM3). The model was driven with monthly climatologies of sea ice fractions derived from three of these records to investigate potential implications of sea ice inaccuracies for climate simulations. The standard sea ice climatology from the Met Office provided a control. This study focuses on the effects of actual inaccuracies of concentration retrievals, which vary spatially and are larger in summer than winter.

The smaller sea ice discrepancies in winter have a much larger influence on climate than the much greater summer sea ice differences. High sensitivity to sea ice prescription was observed, even though no SST feedbacks were included. Significant effects on surface fields were observed in the Arctic, North Atlantic, and North Pacific. Arctic average surface air temperature anomalies in winter vary by $2.5^{\circ} \mathrm{C}$, and locally exceed $12^{\circ} \mathrm{C}$. Arctic mean sea level pressure varies by up to $5 \mathrm{mb}$ locally. Anomalies extend to $45^{\circ} \mathrm{N}$ over North America and Eurasia but not to lower latitudes, and with limited changes in circulation above the boundary layer. No statistically significant impact on climate variability was simulated, in terms of the North Atlantic Oscillation. Results suggest that the uncertainty in summer sea ice prescription is not critical but that winter values require greater accuracy, with the caveats that the influences of ocean-sea ice feedbacks were not included in this study.
\end{abstract}

\section{Introduction}

Arctic sea ice is an important part of the global climate system, primarily due to its modulation of oceanatmosphere fluxes, strong influence on surface albedo, and its effect on ocean buoyancy. Evidence from recent observational records shows that the Arctic sea ice cover is decreasing at a rate of approximately $3 \%$ decade $^{-1}$ (Johannessen et al. 2004; 7.4\% decrease in annual sea ice area from 1978 to 2003), with record-low September minimum ice extents in 2002 (Serreze et al. 2003), 2003, and 2004. The ice cover has thinned by $>1$ m over four decades (Rothrock et al. 1999), while the surface temperature has increased by $0.4 \mathrm{~K}$ de$\mathrm{cade}^{-1}$ (Comiso 2003). There is general agreement in climate prediction scenarios for enhanced warming in

Corresponding author address: Dr. J. S. Singarayer, School of Geographical Sciences, Bristol University, University Rd., Bristol BS8 1SS, United Kingdom.

E-mail: joy.singarayer@bris.ac.uk the Arctic, and that changes in the Arctic sea ice cover may be an early indicator of global warming (Johannessen et al. 1999). Numerical models are frequently used to complement observational studies in order to better understand the climate system and climate change. Modeling of the Arctic climate system, especially the interaction of sea ice with the climate, is complex but has been of considerable recent interest due to its potential to provide early signals of global warming (e.g., Gregory et al. 2002; Gates et al. 1999; Hu et al. 2004; Saenko et al. 2004). The predicted trends of sea ice decreases vary considerably across various models (Walsh and Timlin 2003). The representation of sea ice when under global warming scenarios has been found to influence the simulated behavior of the meridional overturning circulation (Saenko et al. 2004) and Arctic climate sensitivity (Hu et al. 2004). A number of recent studies have also utilized sea ice datasets to drive atmospheric models for the purpose of investigating the atmospheric response to sea ice anomalies (Alexander et al. 2004; Magnusdottir et al. 2004; Deser et al. 2004). 
Consequently, the specification of sea ice fields and their variation has become important, as accurate representations are essential both for driving atmospheric models and for the evaluation of coupled GCMs (with modeled sea ice).

Regular observations of sea ice have been made feasible with the introduction of routine satellite imaging in recent decades. There are several continuous observational datasets of sea ice concentration available that cover the recent period. Multichannel passive microwave radiometer (PMR) data has been used to derive records of sea ice concentrations since 1978 using the Nimbus-7 Scanning Multichannel Microwave Radiometer (SMMR; 1978-87) and the Special Sensor Microwave Imager (SSM/I; since 1987). Various algorithms have been formulated to derive sea ice concentration values from raw PMR data, for example, the National Aeronautics and Space Administration (NASA) team (Cavalieri et al. 1991) and Bootstrap (Comiso 1995) algorithms. Sea ice concentration datasets for the Arctic and Antarctic that have been compiled using these different algorithms are publicly available (e.g., Cavalieri et al. 2002; Comiso 2002).

The U.S. National Ice Center (NIC) has released weekly operational ice charts of sea ice concentrations spanning 1972-94, providing complete coverage of the Arctic (Tanis and Smolyanitsky 2000). Several sources of information were used to produce each chart, largely from satellite data [visible IR from the Advanced Very High Resolution Radiometer (AVHRR) and Operational Line Scan (OLS), SMMR, and SSM/I], ship, and aerial reconnaissance data. Having been manually compiled from several sources by experienced analysts, this dataset may arguably be one of the highest-quality records over the satellite era.

Discrepancies arise between datasets due to the varying sources and processing methodologies used to derive them (Comiso et al. 1997; Singarayer and Bamber 2003). For example, the difference in the total Arctic ice-covered area between the NASA team PMR data and the NIC ice charts can be over $20 \%$ in the summer months (Partington et al. 2003; Singarayer and Bamber 2003).

Ice concentration and ice area are important variables in climate modeling due to their effect on oceanatmosphere exchange of heat and moisture, and surface albedo. Heat flux from the ocean to the atmosphere within leads (areas of open water within the ice pack) can be one or two orders of magnitude greater than through the ice cover even though being only a few percent of the surface area of ice (Maykut 1978). Therefore, the difference in concentrations between the datasets may have a measurable effect on simulation results and is thus an issue requiring investigation.

In a previous study to examine the sensitivity of climate simulations [using the Goddard Institute of Space Studies (GISS) GCM] to prescribed sea ice concentrations, Parkinson et al. (2001) found that uniform biases of $\pm 7 \%$ in concentrations (using NASA team algorithm-derived PMR data) could affect regional temperatures by over $6^{\circ} \mathrm{C}$, and global surface air temperatures by $0.27^{\circ} \mathrm{C}$. Biases of $\pm 7 \%$ were used to provide limits of the impact on climate simulations of the average accuracy of satellite retrievals using SMMR (original data from 1979-86). In the study by Parkinson et al. (2001) the sea ice fields were given uniform and constant biases. The actual accuracies of the concentration retrievals vary spatially and are larger in summer than winter.

Given the number of observational datasets of sea ice concentrations and the considerable differences between them, it is worthwhile considering the potential effect of these differences on the simulated climate and understanding of their associated uncertainties and potential limitations for their use for driving/validating climate models. The aim of the study is to investigate whether the differences in sea ice climatologies are large enough to significantly impact modeled Arctic climate biases or interannual variability. To achieve this, the third Hadley Centre Atmospheric Model (HadAM3) has been forced with three separate sea ice climatologies, based on the NASA team and Bootstrapderived PMR datasets, and the NIC records. In addition, the standard HadAM3 United Kingdom Met Office (UKMO, herafter Met Office) sea ice input climatology was used to drive the model for comparison.

In section 2, we describe the attributes of the different sea ice records. In section 3, we describe the experimental design, and sections 4 and 5 examine the effects on the mean and variability of climate. The paper concludes with a discussion of the results and the significance for climate modeling and new observations of sea ice.

\section{Arctic sea ice concentration dataset intercomparison}

\section{a. Dataset formulation and data sources}

Two of the sea ice datasets used here are derived solely from combined PMR data from the Nimbus-7 SMMR and the Defense Meteorological Satellite Program (DMSP) SSM/I. The SMMR provided horizontally $(\mathrm{H})$ and vertically $(\mathrm{V})$ polarized data at $6.6,10.7$, 18, 21, and $37 \mathrm{GHz}$ from 1978 to 1987. The SSM/I has provided $\mathrm{H}$ and $\mathrm{V}$ polarized data at 19,37 , and $85 \mathrm{GHz}$, 
and vertically polarized data at $22 \mathrm{GHz}$ since 1987 . Sea ice concentrations derived from these data using the NASA team (Cavalieri et al. 1984) and the Bootstrap (Comiso 1995) algorithms are available from the National Snow and Ice Data Center (NSIDC).

The NASA team algorithm was originally developed for use with SMMR but has been modified (Cavalieri et al. 1991) for use with SSM/I. The observed brightness temperatures, $T_{B}$, from the $19 \mathrm{~V}, 19 \mathrm{H}$, and $37 \mathrm{~V}, \mathrm{SSM} / \mathrm{I}$ channels are used to obtain two radiance ratios that are used to solve for ice concentrations. In winter/spring first-year and multiyear ice types can be resolved using this method. The advantage of defining radiance ratios is that they are largely independent of temperature fluctuations. Due to changes in ice/water signatures with season or region a series of open-water and ice tie points are used based on hemispheric analysis of $T_{B}$ values.

The Bootstrap algorithm (described in detail in Comiso 1995) is based on distributions of multichannel clusters of brightness temperatures. It utilizes different channels to the NASA team algorithm. Scatterplots of $37 \mathrm{H}$ versus $37 \mathrm{~V}$ and $19 \mathrm{~V}$ versus $37 \mathrm{~V}$ are created to derive ice concentration. An assumption with this algorithm is that there are large areas within the central Arctic in winter where ice concentrations are $100 \%$. With the current dataset, revised tie points have been used that give better area/extent for periods of sensor overlap. The tie points are adjusted each day to allow better handling of temperature and emissivity fluctuations.

Both the NASA team and Bootstrap derived ice concentration records are available from the NSIDC on a polar stereographic projection where grid cells at $70^{\circ}$ latitude are $25 \mathrm{~km} \times 25 \mathrm{~km}$. During the SMMR period, data were collected every other day; SSM/I data were collected daily.

The NIC ice charts are compiled from operational ice charts for military, commercial, and scientific purposes. They were originally in paper form and manually compiled from various data sources. The charts have been digitized and provide complete coverage of the Arctic (over $45^{\circ}$ latitude) on a weekly basis from 1972 to 1994 , available also from the NSIDC (Tanis and Smolyanitsky 2000). Data sources include the Very High Resolution Radiometer (VHRR) and AVHRR, OLS, PMR from SMMR and SSM/I, ship and aerial reconnaissance, and drifting buoys. The method for obtaining ice concentrations from PMR used by the NIC is the calibration/validation (CAL/VAL) algorithm (Hollinger et al. 1991). This algorithm is similar to the Bootstrap in the channel combinations used. It utilizes the $19 \mathrm{~V}$ and $37 \mathrm{~V}$ channels in the inner ice pack, and the $37 \mathrm{~V}$ and
$37 \mathrm{H}$ channels near the ice edge. The use of this channel at the ice edge provides greater accuracy due its smaller footprint. PMR data were used where higher-resolution data were not available (Partington et al. 2003), due to weather or illumination. Therefore the NIC record is only semidependent on PMR data, with greater reliance on PMR in the central/high Arctic.

The detail, range, and complexity of data and level of expertise have increased over time, and the NIC charts develop from relatively coarse in the 1970s to a highly detailed product in the 1990s (Partington et al. 2003). The NIC charts are available on an Equal-Area Scalable Earth (EASE) grid (a North Polar azimuthal equal-area projection) for the Northern Hemisphere over $45^{\circ}$ latitude, with a nominal grid cell size of $25 \mathrm{~km}$ $\times 25 \mathrm{~km}$.

\section{b. Initial comparisons}

For the purposes of this study the temporal resolution of these datasets has been downscaled to monthly averages. For direct comparison all data were reprojected onto the EASE grid used by the NIC. Gaps in the PMR data directly over the Poles for the NASA team and Bootstrap records were filled with $95 \%$ ice concentrations, similar to the high concentrations observed in the NIC charts. Analyses and comparisons of sea ice extent/area and temporal/spatial variability were reported in Singarayer and Bamber (2003).

Figure 1 shows monthly, integrated ice-covered extent and area (ice-covered area is the fraction of a grid cell that is ice covered multiplied by area of cell, summed for all points; extent is the sum of the areas of all nonzero sea ice grid cells) averaged over the time period of overlap between the sea ice records, 1979-94. The Arctic ice cover, as found in all the datasets, reaches its maximum extent in March of $\sim 15 \times 10^{6} \mathrm{~km}^{2}$, and has a minimum in September of $\sim 8 \times 10^{6} \mathrm{~km}^{2}$. In both ice-covered area and extent the NIC records produce significantly larger values than the PMR datasets. While the Bootstrap and NASA team PMR extents are very similar (generally only $1 \%-2 \%$ difference) there is a larger difference in their derived areas. The NIC icecovered area is greater than the NASA team area by $5 \%-10 \%$ for most of the year, which rises up to $23 \%$ larger in July/August (found also by Partington et al. 2003). The difference between the Bootstrap and NIC areas is also largest in July. The difference between the two PMR datasets is greatest in late summer (which compares with the findings of Comiso et al. 1997). The derived sea ice extents and areas are most similar during autumn/winter.

To illustrate this further, Fig. 2 shows mean ice concentration maps for (Fig. 2a) March 1994 and (Fig. 2b) 

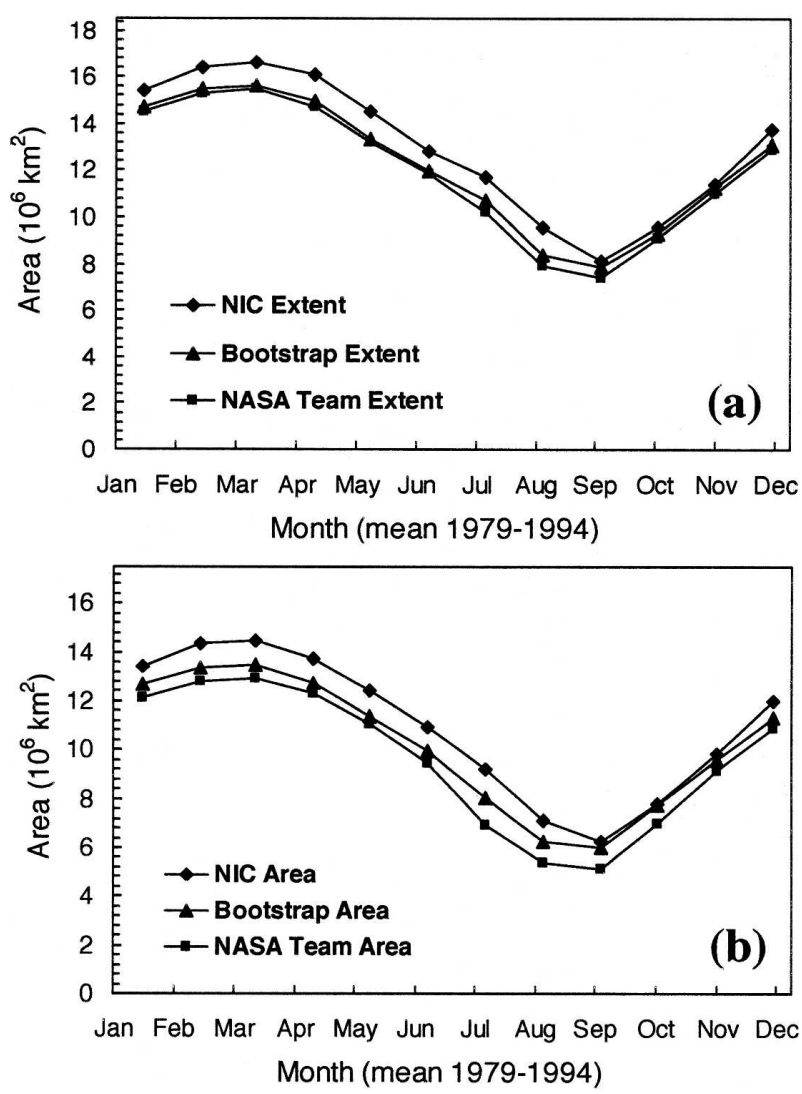

FIG. 1. Comparison of mean seasonal variation in Arctic (a) ice extent and (b) ice-covered area from three different records of sea ice concentration. Area is calculated for ice concentrations $>15 \%$ over the period 1979-94.

September 1994. The maps in winter (Fig. 2a) are more similar than in summer (Fig. 2b). Concentrations in the Central Arctic in winter are in general agreement. However, near the ice edge in the Bering and Labrador Seas and the Sea of Okhotsk the NASA team concentrations are considerably lower than the NIC and the Bootstrap data. In September 1994, ice concentrations in the East Siberian Arctic are much lower in the NASA team record than either the NIC or Bootstrap datasets (Fig. 2b). The lower concentrations extend over a more extensive area in summer than winter, in general. The NASA team algorithm is insensitive to thin ice and can incorrectly interpret large areas of thin ice as lower concentrations of thicker ice. On the other hand, the NIC chart data compilation include higherresolution sources and use the CAL/VAL algorithm for PMR data, which is optimized for thin ice near the ice edge, due to the original operational purposes of the charts. However, the CAL/VAL algorithm tends to saturate to $100 \%$ in the high Arctic due to its inability to detect fine differences in concentrations in regions of near-complete ice cover (Meier et al. 2001). Conse- quently, the concentrations in the inner ice pack may be unrealistically high and unvarying. The Bootstrap maps show similarly high concentrations in the central Arctic. The algorithm was devised using the assumption that large areas of the inner ice pack in winter will have concentrations of near $100 \%$.

The largest differences occur between the NIC and the NASA team data in the summer months. PMR data particularly suffer from an inability to distinguish areas of summer surface meltwater (melt ponds) from open water, resulting in artificially low concentrations. Since the NIC dataset is not as reliant on PMR data this is not such a problem. The fact that the largest differences between the sea ice concentration datasets occur in summer suggests the effect of surface melt ponds on PMR ice concentration retrievals is one of the main causes of the discrepancies, and that it affects the NASA team-derived values in particular.

Agreement between the PMR datasets (Bootstrap and NASA team) is greatest in winter in the central Arctic. Differences are largest in summer and in regions of seasonal ice cover (Comiso et al. 1997). The Bootstrap makes use of the higher-resolution $37-\mathrm{GHz}$ $\mathrm{H}$ and $\mathrm{V}$ channel combination in the perennial ice region, whereas the NASA team uses the polarization and gradient ratios as discussed earlier. Both algorithms use the 22-GHz channel to mask out open ocean but in combination with different channels and using different threshold values potentially giving slightly different marginal ice zone locations (Comiso et al. 1997).

\section{c. Associated uncertainties}

The uncertainty in ice concentration retrieval is a combination of random and systematic errors, and is both temporally and spatially dependent. The errors associated with each dataset are difficult to quantify due to the nonuniform and evolving nature of the ice, cover. For example, the emissivity changes with the type of ice from new ice, first-year ice and multiyear ice. The uncertainty, especially in the records using solely PMR data, will be greater in summer due to snow and ice melt and surface meltwater areas. This is when the greatest discrepancies in ice concentrations occur.

Gloersen et al. (1992) considered that a figure of $\pm 7 \%$ was a reasonable overall estimate of accuracy for SMMR and SSM/I data. The NASA team dataset accuracy (Cavalieri et al. 2002) is given as approximately $5 \%$ in general, increasing to around $15 \%$ for the Arctic in summer. Better accuracy is obtained within the central ice pack where the ice cover is thicker, and decreases as the proportion of thin ice increases. Similarly, the Bootstrap dataset overall accuracy is quoted as $5 \%-10 \%$ (Comiso 2002) except where there is an 

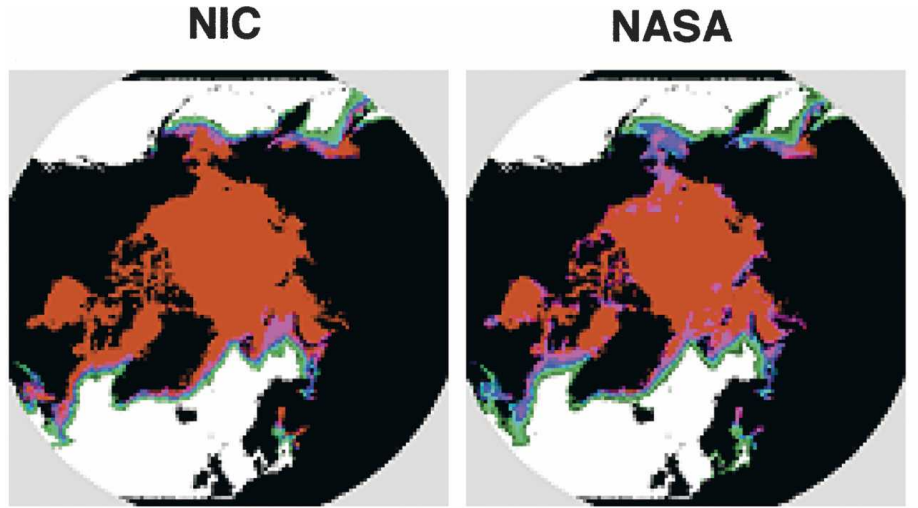

\section{Bootstrap}

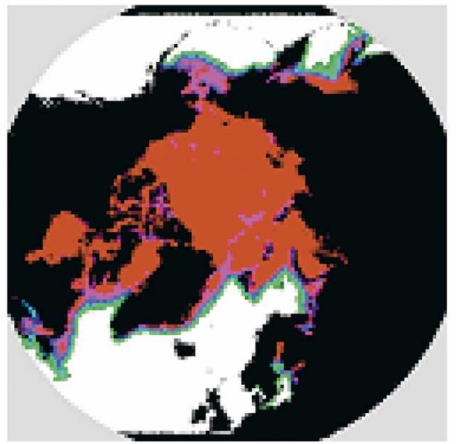

(a) March 1994
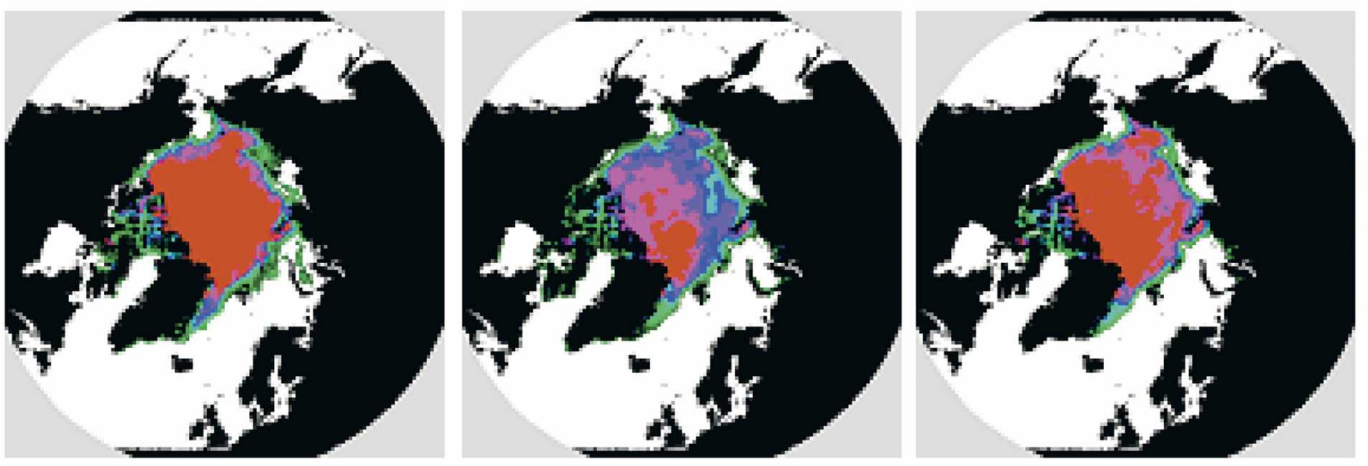

(b) September 1994

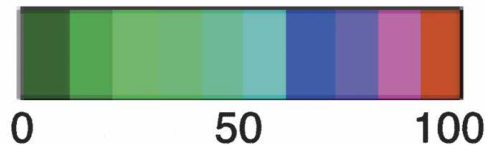

FIG. 2. Example of monthly mean maps of Arctic sea ice concentrations from (a) Mar and

(b) Sep 1994, for each of the records: NIC, NASA team, and Bootstrap.

unusually large fraction of thin ice or melt ponds. The NIC charts have been through a number of quality reviews and error reduction in the process of digitization. The manual compilation of the ice charts from several sources of data and the quality assurance process undertaken by the NIC should mean that these charts are of a higher quality and accuracy. However, because of the changes in data sources used and experience of analysts errors/biases may have been introduced that are difficult to quantify, for example, systematic overor underestimation by analysts, which was accounted for by assigning $\pm 1 / 10$ ice concentration uncertainty (Partington et al. 2003).

\section{d. Previous dataset validation}

Validation of these datasets with higher-resolution/ ground truth instruments has been difficult due to lack of comparable spatial coverage. A validation study performed by Steffen and Schweiger (1991) found greater differences between SSM/I NASA team concentrations and Landsat-derived concentrations in summer than in spring and autumn. For example, in the Beaufort and Chukchi Seas, the difference between NASA team and Landsat was $0.6 \% \pm 7.4 \%$ in autumn, $-2.1 \% \pm 3.1 \%$ in spring, and $11.0 \% \pm 22.9 \%$ in summer. However, another comparison of SSM/I NASA team data to AVHRR calculated a $6 \%$ difference, which reduced to only $3 \%$ in summer (Emery et al. 1994), while Bootstrap data differed by $5 \%$ in both seasons (however, Bootstrap tie points have since been adjusted).

Comiso et al. (1997) extended the results of Steffen and Schweiger (1991). The differences between Landsat and Bootstrap Arctic values were generally negative in low concentrations and positive in areas of high concentrations. The difference in the absolute mean between the NASA team and Landsat was $8.2 \%$, and between Bootstrap and Landsat, it was $6.1 \%$.

Comiso and Kwok (1996) compared PMR, synthetic aperture radar (SAR), and AVHRR to study the effect 
of the onset of melt, melt ponding, and freeze up. In summer, a large portion of the inner ice pack has concentrations $\sim 90 \%$ by SAR and AVHRR, substantially higher than PMR retrievals. The Bootstrap did give better consistency with SAR according to the study though.

The studies performed show that each of the datasets has their strengths and weaknesses. However, it is difficult to demonstrate that one dataset is more reliable overall.

\section{Experimental details}

\section{a. Atmosphere}

The atmospheric model, HadAM3, is a component of the coupled HadCM3 model, a version of the Met Office unified forecast and climate model. HadAM3 is run at a horizontal resolution of $2.5^{\circ}$ latitude $\times 3.75^{\circ}$ longitude using 19 vertical hybrid coordinate levels and a time step of $30 \mathrm{~min}$.

In version 3 of the Hadley atmospheric model a new radiation scheme (Edwards and Slingo 1996) is incorporated, modified by Cusack et al. (1998). It has six shortwave bands and eight longwave bands and includes the effects of $\mathrm{CO}_{2}, \mathrm{H}_{2} \mathrm{O}, \mathrm{O}_{3}, \mathrm{O}_{2}, \mathrm{~N}_{2} \mathrm{O}, \mathrm{CH}_{4}$, and chlorofluorocarbons (CFCs). The model simulations required concentrations of trace gases appropriate for the time period of the sea ice datasets, $1979-1994\left(\mathrm{CO}_{2}\right.$ : 345 ppmv, $\mathrm{CH}_{4}: 790$ ppbv, $\mathrm{N}_{2} \mathrm{O}: 284$ ppbv, CFC11: 221 pptv, CFC12: 381 pptv). A prognostic cloud scheme (Gregory and Morris 1996) is used in the model, which uses the primary model variables, total moisture, and liquid water potential temperature to diagnose cloud ice, cloud water, and cloud amount. Dry and moist convection are modeled using the mass flux scheme with a parameterization of the direct impact of convection on momentum.

The atmospheric boundary layer can occupy up to the bottom five atmospheric model layers (Johns et al. 1997). A first-order turbulent mixing scheme is used to mix the conserved thermodynamic variables and momentum in the vertical (Smith 1990). A land surface scheme, the Meteorological Office Surface Exchange Scheme (MOSES; Cox et al. 1999), is included which includes a representation of soil moisture freezing and melting and should lead to better simulations of surface temperatures. A zero heat flux condition is imposed at the base of the soil model to conserve heat within the system. Over land, surface roughness characteristics are prescribed according to climatological surface type. At sea points, however, the roughness length over open water is computed from local wind speeds. Where there is partial sea ice cover, separate fluxes are computed for sea ice and leads within a grid box. A small surface areal heat capacity equivalent to about $5 \mathrm{~cm}$ of water is assumed so that the diurnal cycle of surface temperature over sea ice can be resolved. The surface ocean temperature within the leads portion of a partially icecovered grid box is fixed at $-1.8^{\circ} \mathrm{C}$.

Simulated Arctic climate structures may be more sensitive than other regions to boundary layer parameterizations, as found by Dethloff et al. (2001) with the HIRHAM $^{1}$ regional model. The sensitivity of the Arctic climate to sea ice anomalies will depend on the parameterizations used. The HadAM3 boundary layer parameterization uses Monin-Obukhov similarity theory. Dethloff et al. (2001) found this scheme works well over areas of open ocean, although over land the stable boundary layer in winter was underestimated. Lynch et al. (1995) found that the parameterization of atmospheric moist processes (particularly inclusion of ice phase physics in cloud processes, subgrid-scale moisture treatment, and relative humidity threshold for conversion of cloud water to rainwater) has significant impacts on simulation of Arctic climate, most apparent in winter in terms of surface heat fluxes. HadAM3 includes detailed treatment of hydrology, cloud physics, and surface exchange fluxes, among others, which should produce reasonable sensitivity to Arctic sea ice for this study. A full description of the model and revisions made from the previous versions are described in Pope et al. (2000).

HadAM3 was forced with sea ice climatologies based on the sea ice datasets described previously, in conjunction with a modern sea surface temperature (SST) climatology.

\section{b. Model simulations}

Four model experiments were performed with HadAM3, forced with sea ice climatologies derived from the NIC, NASA team and Bootstrap records, and using the Met Office sea ice as a control. To construct the sea ice climatologies from the NIC, NASA team, and Bootstrap records, monthly Arctic sea ice concentration maps for the period 1979-94 were averaged and interpolated onto the Hadley Centre model grid. The ice concentrations were assigned for the midpoint of

\footnotetext{
${ }^{1}$ The acronym HIRHAM comes from the combination of HIRLAM and ECHAM4, indicating that HIRHAM was built from the dynamics of the High Resolution Limited Area Model (HIRLAM), used in Scandinavian countries for weather forecasts and from the physical parameterizations of ECHAM4, the global circulation model from the Max Planck Institute for Meteorology in Hamburg, which has its roots in the European Centre for Medium-Range Weather Forecasts (ECMWF) model.
} 
each month and concentrations $<15 \%$ were set to zero (to eliminate spurious concentrations). The interpolated sea ice fields were examined to ensure that appropriate areas and differences between the datasets were retained after interpolation.

Used to provide a control, the standard Met Office sea ice input field (Jones 1993) generally used to force HadAM3 (e.g., in Pope et al. 2000) is based on automatically decoding bulletins from the Joint Ice Center in Washington. The data are mainly derived from satellite information (Kniskern 1991). The ice edge is mapped as the most equatorward point that is behind the reported sea ice edge. In the Met Office sea ice dataset there are also no ice-covered grid points with a sea ice concentration of less than $50 \%$.

The Antarctic sea ice field in the Met Office sea ice climatology was used in conjunction with the three other sea ice climatologies. Using the same Antarctic sea ice data enabled the experiments performed to solely investigate the impact of changes/variations in Arctic sea ice on the simulated climate.

Also, prescribed in the sea ice boundary conditions is the ice depth. A value of sea ice thickness (depth) is set for all points that have a nonzero value of sea ice. This was set uniformly to $2 \mathrm{~m}$ for the Northern Hemisphere (Arctic) and $1 \mathrm{~m}$ for the Southern Hemisphere (Antarctic) for all the sea ice datasets. Linear interpolation of sea ice fraction is performed in the model between the monthly mean values every 5 days. In the month where all sea ice in a grid cell melts (forms), both the ice fraction and ice depth are decreased (increased) every 5 days to (from) 0 .

We note that using a uniform ice depth of $2 \mathrm{~m}$ may exaggerate the impact of sea ice concentration discrepancies. The largest differences occur near the marginal ice zone, where ice may be thinner. The oceanatmosphere heat flux through thin ice in winter is significantly higher than thick multiyear ice (Maykut 1978). Thus, the differences in the simulated winter climate due to anomalous sea ice concentrations may be regarded as representing the potential maximum impact.

The standard SST field used to force HadAM3 is a climatology based on the Global Sea Ice and Sea Surface Temperature (GISST) climatology (Parker et al. 1995). Data are derived from the GISST2.0 SST record from 1961 to 1990. In situ SSTs for 1961-90 were merged with statistically derived values for sea ice regions using observed sea ice concentrations. The monthly fields have previously been smoothed and averaged onto the HadAM3 grid. The SSTs used for this study have been modified from this standard SST field. In the original dataset all points with a nonzero sea ice
TABLE 1 . Summary of the four simulations performed in the study.

\begin{tabular}{lc}
\hline $\begin{array}{c}\text { Experiment } \\
\text { name }\end{array}$ & \multicolumn{1}{c}{ Description } \\
\hline CONTROL & $\begin{array}{c}\text { HadAM3 + UKMO climatological sea ice (no } \\
\text { ice concentrations }<50 \%)\end{array}$ \\
NT & $\begin{array}{c}\text { HadAM3 + PMR NASA team sea ice }(>15 \% \\
\text { concentrations) }\end{array}$ \\
BOOT & $\begin{array}{c}\text { HadAM3 + Bootstrap derived PMR } \\
\text { concentrations }(>15 \% \text { concentrations) }\end{array}$ \\
NIC & $\begin{array}{c}\text { HadAM3 + National Ice Center gridded sea ice } \\
\text { concentrations }(>15 \% \text { concentrations) }\end{array}$ \\
\hline
\end{tabular}

fraction were given a sea surface temperature of 271.35 $\mathrm{K}$ (i.e., the freezing point of saline water). Examination of the original SST and the three specifically interpolated sea ice fields showed a number of nonzero ice points in the Northern Hemisphere with SSTs in excess of the freezing temperature of seawater (up to $10 \mathrm{~K}$ over). Therefore the SST field was modified so that a minimum sea ice fraction of 0.1 for ice-covered points was used with maximum 0.8 -K SST above freezing for nonzero ice fraction grid points. Changes to the SST field were made only in the Northern Hemisphere. The resulting SST climatology was then used in all four simulations.

The model experiments are summarized in Table 1. Forty-one model years were run for each of the simulations and the last $33 \mathrm{yr}$ were integrated (initial $8 \mathrm{yr}$ of spinup time was discarded). The results from the Met Office sea ice experiment are labeled as CONTROL, against which the other experiments are compared; the NASA team (NT), Bootstrap (BOOT), and NIC experiments.

By varying the sea ice input field using different datasets this study will include the impact on simulated climate of both systematic biases and random errors. The main aim of this part of the study is to investigate how important the choice of sea ice dataset is when simulating climate. The effects of the larger summer discrepancies, considered to be mainly due to summer surface melt retrieval inaccuracies can also be investigated by using differently sourced sea ice observations.

\section{Comparison of mean climate}

a. Surface fields

\section{1) Surface Air Temperature}

There are significant differences in surface air temperatures (SAT) in the Northern Hemisphere in autumn, winter, and early spring only. Global annual 


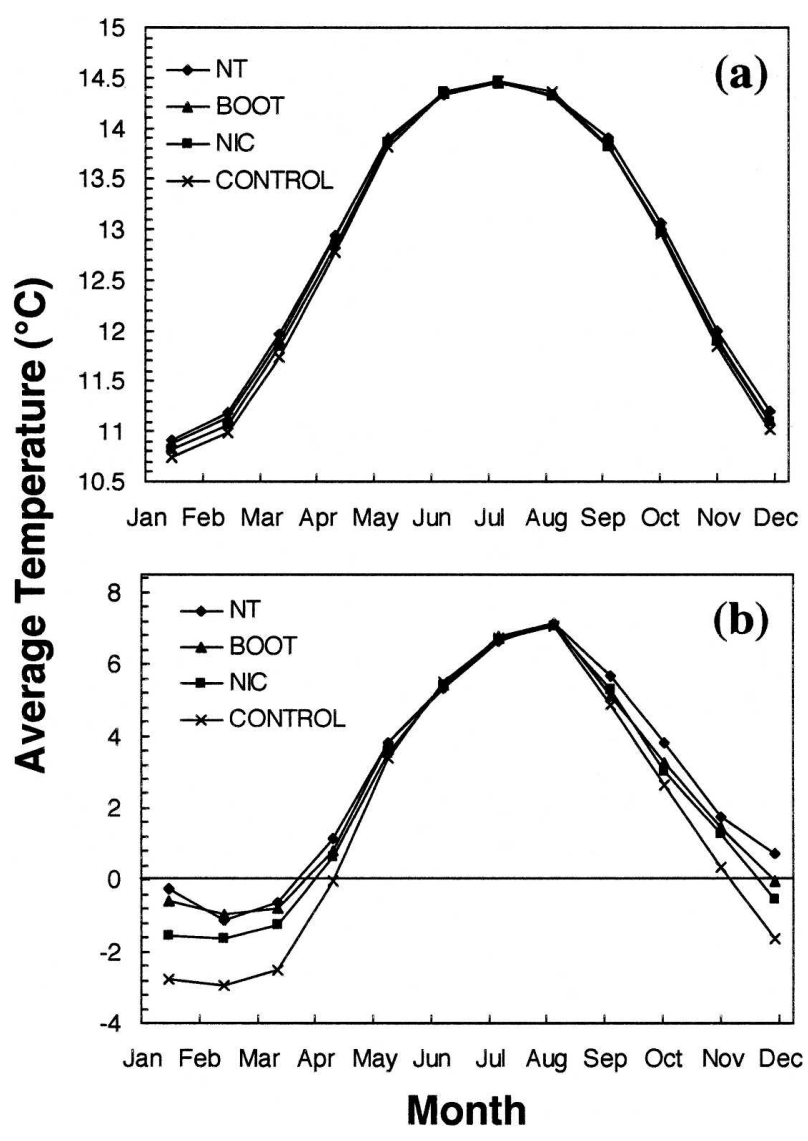

FIG. 3. (a) Global monthly average surface air temperature (1.5-m temperature, ${ }^{\circ} \mathrm{C}$ ) from the four climate simulations. (b) Average monthly Arctic temperatures $\left(60^{\circ}-90^{\circ} \mathrm{N}\right)$.

mean temperatures differ by $0.11^{\circ} \mathrm{C}$, from $12.74^{\circ} \mathrm{C}$ in the CONTROL experiment to $12.85^{\circ} \mathrm{C}$ in the NT experiment. As found by Pope et al. (2000) HadAM3 compared to the ECMWF Re-Analysis (ERA) data is too cold near the surface, with the largest cold biases in the Northern Hemisphere in winter. The global means are in fact slightly colder than in other simulations using HadAM3, which is probably a result of cooling the SSTs in general to fit with the more extensive sea ice records.

Illustrated in Fig. 3a is the average monthly global temperature from each climatological run. The largest differences occur in winter, whereas in the summer months the differences in global SATs are less than $0.02^{\circ} \mathrm{C}$. The greatest SAT differences occur over the Arctic, as shown in Fig. 3b. Averaged over $60^{\circ}-90^{\circ}$ latitude, differences as large as $2.5^{\circ} \mathrm{C}$ occur in winter, where the lowest temperatures are simulated in the CONTROL and NIC experiments. In summer, however, there is no statistically significant difference, resulting in a greater seasonality of the CONTROL and
NIC Arctic temperatures compared with the PMR (NT and BOOT) simulated seasonal SAT cycles. There are no statistically significant differences at low latitudes. [Parkinson et al. (2001) found that even with uniform sea ice concentration differences as large as $50 \%$ most of the temperature changes outside polar regions were not significant.]

The Met Office sea ice extent (used in the CONTROL) is smaller than the other datasets; however, it has high concentrations in general over the Arctic, similar to the NIC climatology, whereas the NASA team field has the lowest concentrations of all the datasets. The oceanatmosphere heat flux through areas of open water within the ice pack in winter can be several orders of magnitude greater than through the ice cover (Maykut 1978). The lower concentrations (i.e., greater openwater area within the ice pack) result in warmer surface air temperatures in the NT and BOOT simulations primarily through ocean heat loss.

The spread between the sea ice records and retrieval inaccuracies are greatest in the summer months largely due to surface melt pond areas. These differences in ice coverage, which are as large as the area of Greenland (Partington et al. 2003) make relatively little impression on the simulated summer climate compared with the much smaller winter ice retrieval discrepancies. This is because the surface heat fluxes are much smaller due to reduced ocean-atmosphere temperature gradients (see section 4b). In reality, sea surface temperatures may increase where summer sea ice concentrations are lower due to greater radiative absorption by the ocean. Including this effect might influence the differences in the simulated summer temperatures. However, increases in summer SSTs due to lower sea ice concentrations are restricted in any case by the input of sea ice meltwater at (at approximately $0^{\circ} \mathrm{C}$ ). Therefore, we would not expect largely different results to those presented here using fixed a SST field.

All further analysis will concentrate on simulated winter anomalies, given the lack of response in the summer months to sea ice prescription. The mapped distribution winter [December-January-February (DJF)] SAT for the CONTROL simulation and differences from the other three experiments are shown in Fig. 4 (left-hand plots). In general Arctic temperatures in the NT, NIC, and BOOT experiments are significantly higher than the CONTROL (areas of statistically significant changes are enclosed by the black contour lines in the figures, at the $95 \%$ confidence level, calculated using $t$-test statistics). Positive anomalies occur mainly over the ice-covered ocean and extend over land into northern Eurasia. The largest increases occur in the marginal ice zone, directly over the areas of largest 

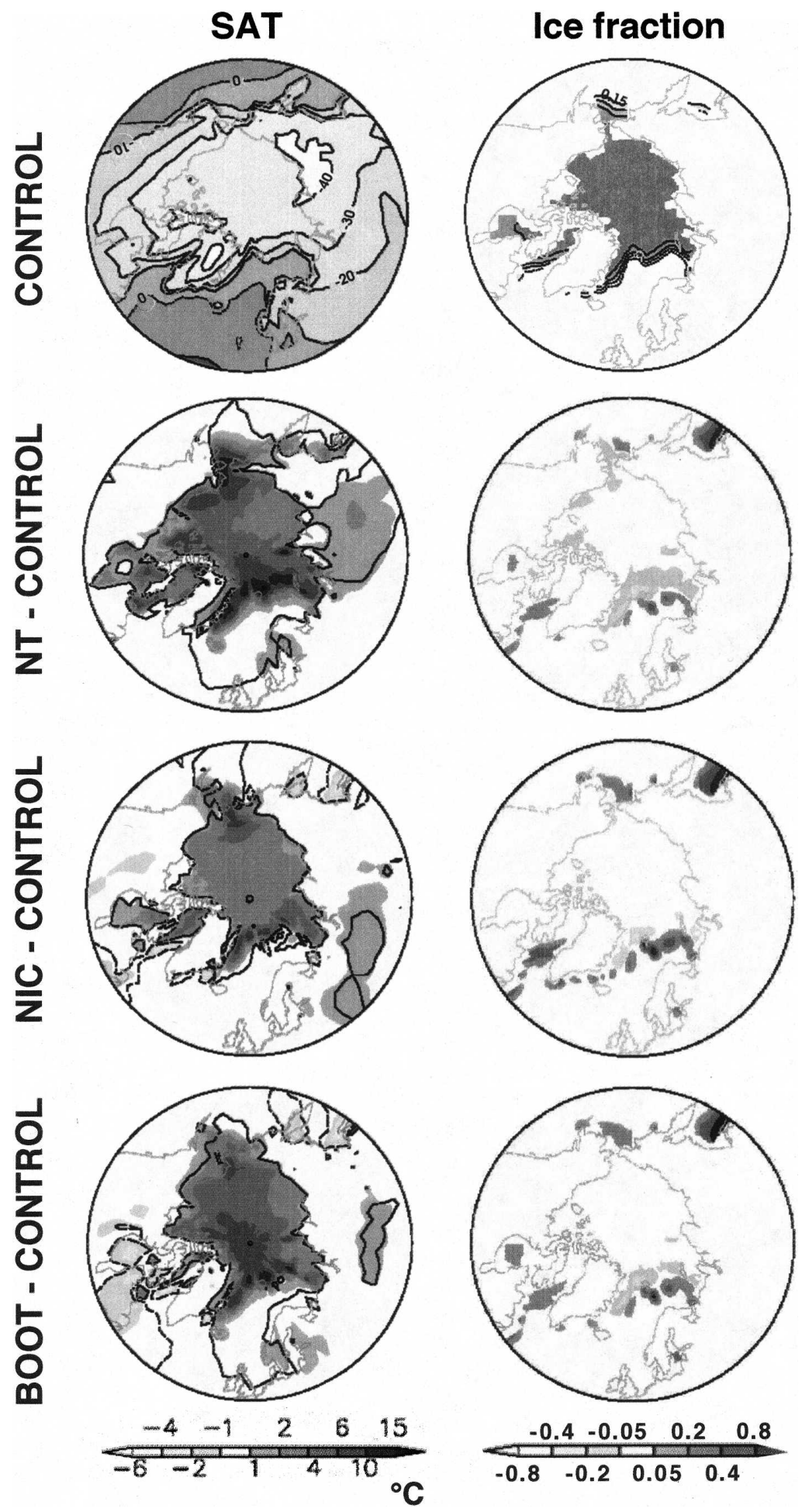

FIG. 4. (right) Prescribed winter (DJF) sea ice fractions and (left) winter SATs from (top) the CONTROL simulation and anomalies: (NT - CONTROL), (NIC CONTROL), and (BOOT - CONTROL). (top right) Contours for the CONTROL ice fractions are $0.15,0.4,0.65$, and 0.9 . The shading keys are associated with the anomaly plots. (right) Areas enclosed by the contour lines in the SAT anomalies represent statistically significant differences at the $95 \%$ confidence level (solid line $=$ positive anomalies, dotted line $=$ negative anomalies). 
negative discrepancies in sea ice fraction. Ice fraction anomalies are also shown in Fig. 4 (right-hand plots). Over the central Arctic Ocean and near the marginal ice zone the NT and BOOT ice fractions (and to a lesser degree, the NIC fractions) are lower than the CONTROL. The largest negative discrepancies occur between the NT and CONTROL ice fractions, the locations of which correspond to the largest SAT increases that exceed $12^{\circ} \mathrm{C}$ in places (see Fig. 4, NT CONTROLplots).

The extent of the ice cover in the CONTROL is smaller than the other three climatologies, giving the positive ice fractions anomalies seen at the ice edge in the ice fraction anomalies in Fig. 4. Where this occurs in the Greenland-Iceland-Norwegian (GIN) and Bering Seas it does not lead to temperature decreases (due, in part to changes in low-level circulation, see next section). However, over the Labrador Sea (southeast of Greenland) and over the Sea of Okhotsk, on the Pacific side, the positive ice fraction anomalies do lead to significant temperature decreases in the NIC and BOOT simulations, compared to the CONTROL.

SAT increases over Northern Hemisphere land due to sea ice discrepancies occur over the Canadian Archipelago, the northeast coast of Greenland, and northern Eurasia in the NT, NIC, and BOOT simulations compared with the CONTROL, but do not extend to lower latitudes. The temperature changes over Eurasia are due to sea ice-induced changes in circulation, which are discussed in the next section.

In areas of ocean that are not covered by sea ice the differences in temperature are suppressed due to the prescription of the same SSTs in each simulation. Consequently, significant differences in SAT occur primarily over and near ice-covered seas and over land down to the midlatitudes. Outside Arctic regions temperature anomalies tend to be $<1^{\circ} \mathrm{C}$. Temperature anomalies are not well propagated vertically either. Significant changes in modeled temperature do not propagate vertically beyond $\sim 700 \mathrm{hPa}$ (similar results have been found by Magnusdottir et al. (2004) and Alexander et al. (2004).

\section{2) Sea Level Pressure and Circulation}

Differences in simulated mean sea level pressure (MSLP) occur mainly at high latitudes in winter and are a local rather than large-scale response to sea ice discrepancies. The wintertime Icelandic low, Aleutian low, and Azores high occur at similar positions in all of the simulations (MSLP from the CONTROL run is shown in Fig. 5, upper-left plot). Mean sea level pressure anomalies with the NT simulation are given in the lower-left plot (Fig. 5). Only NT - CONTROL anomalies are displayed in the following sections for the reason that these two simulations show the greatest differences and can exemplify similar trends found with the BOOT experiment. The NIC sea ice climatology is the most similar to the CONTROL, also having high concentrations in the central Arctic. However, the trend in anomalies of the NIC simulation with the CONTROL is similar to the NT, albeit much weaker.

In general over the central Arctic region in autumn and winter the NT MSLP is significantly lower than the CONTROL (Fig. 5, lower-left plot) due to its warmer, moister lower atmosphere. In some areas an MSLP decrease of $>4 \mathrm{hPa}$ was seen, mostly over areas of sea ice discrepancy over ocean east of Greenland and into the Barents Sea. The low pressure anomaly reaches down to the Icelandic low and extends on land over Eurasia. Anomalous cyclonic circulation is induced by the low pressure and brings warmer air from the west into northern Eurasia, increasing the winter SAT average over parts of the continent (see Fig. 4; NT - CONTROL SAT). The low pressure over the Arctic also brings warmer air in from lower latitudes over the GIN and Barents Seas, which results in the temperature increases in the NT compared to the CONTROL even over areas in these regions that are ice covered in the NT experiment but not in the CONTROL (see Fig. 4).

Winter average geopotential height anomalies (Fig. 5 lower-middle and lower-right plots) do not show the localized structures seen in the MSLP anomalies that directly corresponded to the location of sea ice anomalies. There are smaller areas where anomalies are significant at 500 and $200 \mathrm{mb}$, enclosed by the black contour lines in Fig. 5. The anomalies do not resemble large-scale structures such as the North Atlantic Oscillation (NAO) and Arctic Oscillation (AO). An anomalous trough at $500 \mathrm{mb}$ occurs over regions of increased ice cover in the NT experiment compared with the CONTROL experiment in the Labrador Sea. This was seen consistently with the NIC and BOOT anomalies, in which it results from a cooler air column directly over regions of enhanced sea ice (see Fig. 4), lowering the height surface. Another anomalous trough occurs over the East Siberian Sea, above the Arctic surface anticyclone (Fig. 5; MSLP). Surface cold high pressure cells weaken with height and are replaced by low pressure above. Warmer SATs and lower MSLP over the Arctic in the NT experiment further enhance this feature. Also consistent in the NT, NIC, and BOOT is the positive height anomaly over western Europe, which is an amplification of the midlatitude ridge. The anomalous ridge intensifies with height. This pattern of change is 

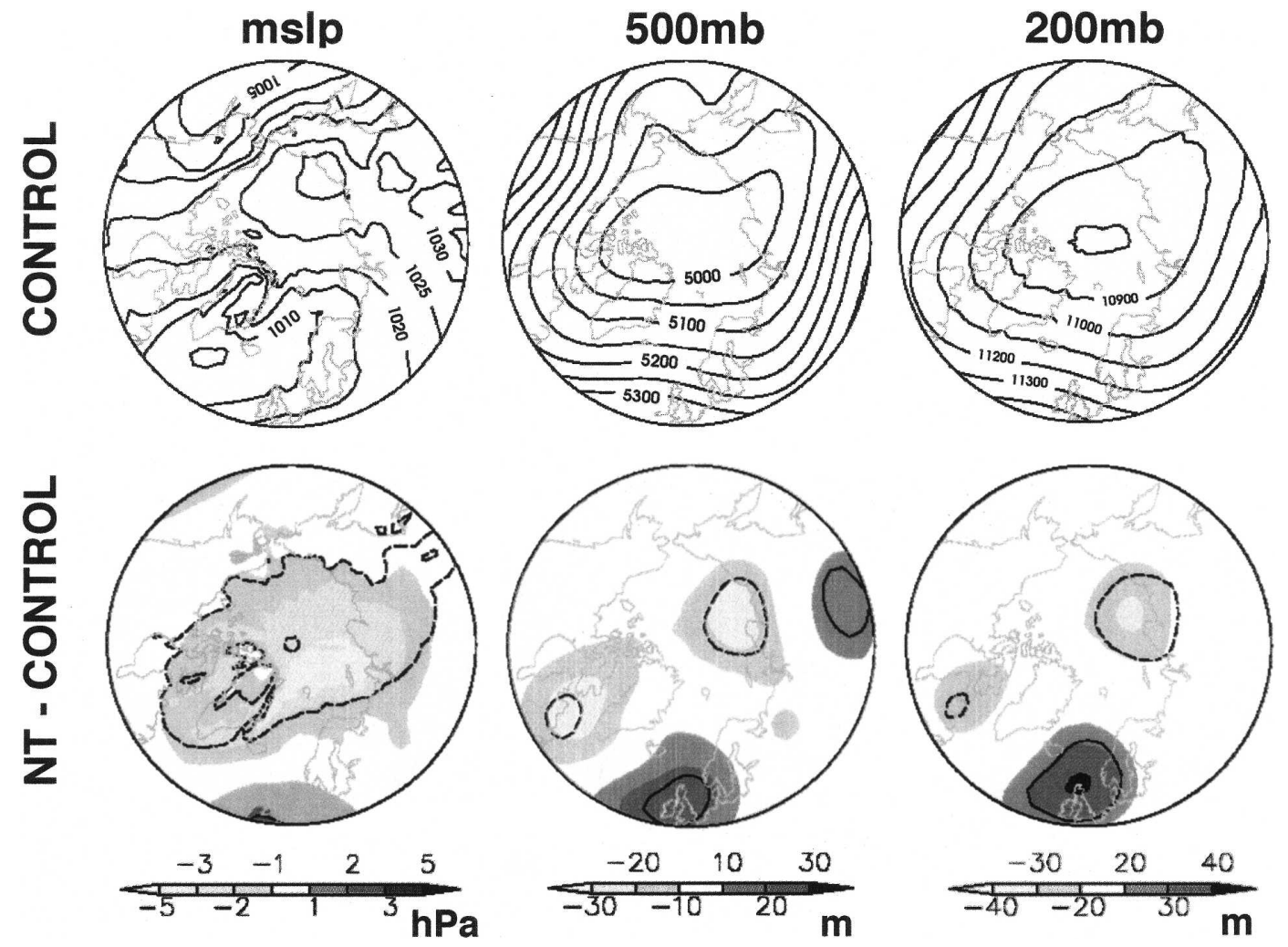

FIG. 5. Winter (DJF) average MSLP from (top left) the CONTROL run and (top middle) 500- and (top right) 200-mb heights. (bottom) Anomalies from the NT simulation are shown with contour lines to represent areas of significant differences (solid line $=$ positive anomalies, dotted line $=$ negative anomalies). The shaded keys are associated with (bottom) the anomaly plots.

consistent with the changes in storm tracks (discussed in section 4c). Valdes and Hoskins (1989) and Hoskins and Valdes (1990) show that storm track-induced feedbacks (direct and via changes in diabatic heating) play a major role in the formation of the ridge. Hence the sea ice-induced strengthening of the storm tracks results in an enhancement in the mean climatological flow.

\section{b. Surface fluxes}

Sea ice fraction directly affects surface fluxes, as it insulates and decouples the ocean from the atmosphere. The surface energy balance is a combination of sensible heat and latent (evaporative) heat fluxes, radiative fluxes (shortwave and longwave), and (small) heat loss through precipitation. In winter there is a small downward heat flux over sea ice and a much larger upward flux over areas of open water. Values of sensible and latent heat fluxes over leads can exceed 400 and $130 \mathrm{~W} \mathrm{~m}^{-2}$, respectively (Andreas et al. 1979). Figure 6 shows the distribution of average winter sensible heat flux for the Northern Hemisphere as simu- lated in the CONTROL (upper-left plot), and anomalies from the NT simulation (lower-left plot). The distribution of anomalies demonstrate that there is a much larger sea-air heat flux (positive anomalies) directly over areas of reduced sea ice fractions, particularly evident near the ice edge. Immediately equatorward of this, the heat loss is larger in the CONTROL, which has greater sea ice fractions near the ice edge. The greater heat loss in these regions is partly due to colder surface air flowing farther south (outside the ice-covered ocean regions), which produces a large sea-air temperature gradient farther south, resulting in a bigger upward (sensible) heat flux, and partly due to lower humidity over the GIN Sea, which allows a larger upward latent heat flux. The maximum differences are $>200 \mathrm{~W} \mathrm{~m}^{-2}$.

In winter the net surface energy balance (Fig. 6, right-hand plots) in the Northern Hemisphere is upward (i.e., heat loss from the ocean to atmosphere), and is greater over the Arctic ice-covered area in the NT experiment than the CONTROL (Fig. 6, lower-right plot). This is due primarily to the greater upward sensible and latent heat fluxes where there is a larger fraction of open water in the NT sea ice climatology. The 


\section{Sensible heat}
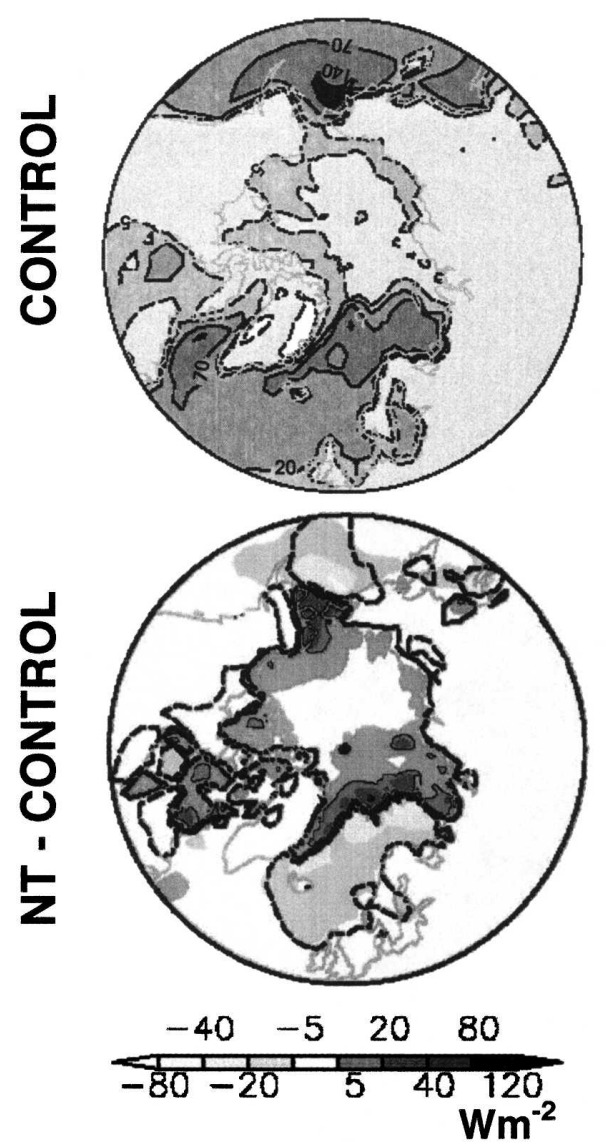

Surface energy balance
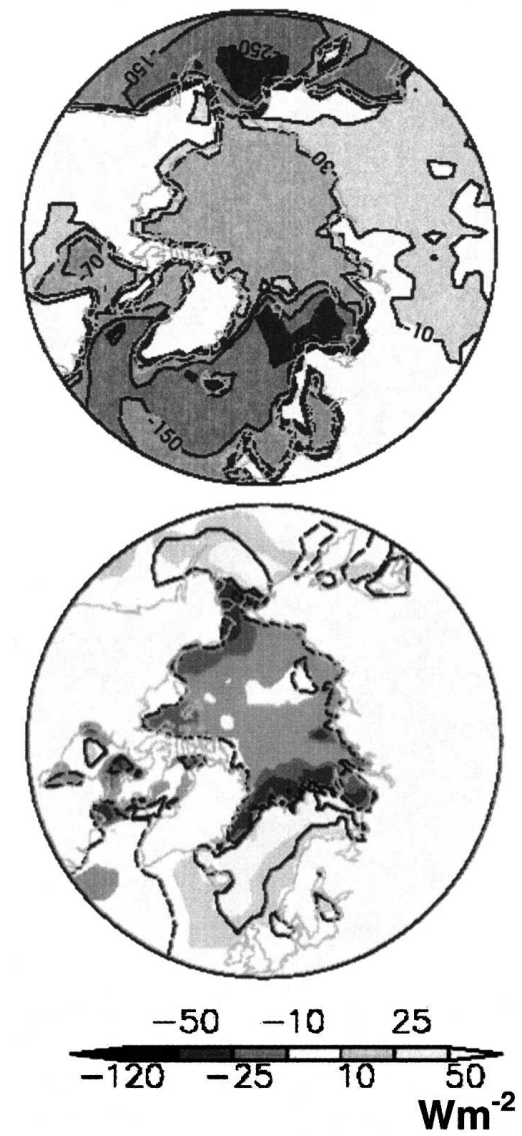

FIG. 6. Winter (DJF) average (top left) sensible heat flux and (top right) surface energy balance from the CONTROL simulation. (bottom) Anomalies from the NT simulation are shown with contour lines to represent areas of significant differences (solid line $=$ positive anomalies, dotted line $=$ negative anomalies). The shaded keys are associated with (bottom) the anomaly plots.

heat flux anomalies lead directly to the positive SAT anomalies in Fig. 4.

The longwave (LW) radiation balance is also important in the winter surface energy balance. Net LW heat loss from the ocean to the atmosphere is greater where there is reduced sea ice, which result in the energy balance anomalies over the high Arctic. In the North Atlantic and North Pacific there is greater upward energy transfer in the CONTROL simulation than the NT simulation. Patterns of anomalies follow the patterns of sensible and latent heat anomalies.

In summer, there are no discernable differences in the modeled heat fluxes (not shown). There is a positive net surface energy balance over the Northern Hemisphere. Over the Arctic in summer there is a greater downward flux in the NT simulation than the CONTROL. The magnitude of the differences, how- ever, is much smaller than in winter. Shortwave (SW) radiation absorption at the surface is the most important factor in the summer net surface energy balance. Sensible and latent heat losses are comparatively small in summer as the sea-air temperature gradient is much less than in winter. The SW incident radiation can be absorbed by open water but is reflected by ice, which has a higher albedo. Therefore, in the NT simulation, which has reduced sea ice concentrations, more of the incident SW is absorbed at the surface, although there is actually less surface downward SW radiation due in part to increased (low) cloud cover over reduced sea ice areas. Despite there being differences in Arctic surface energy balance these do not produce significant differences in surface air temperature in summer.

It is noted that $\mathrm{SW}$ and $\mathrm{LW}$ radiation would heat the oceans radiatively if a coupled model were used. Using 

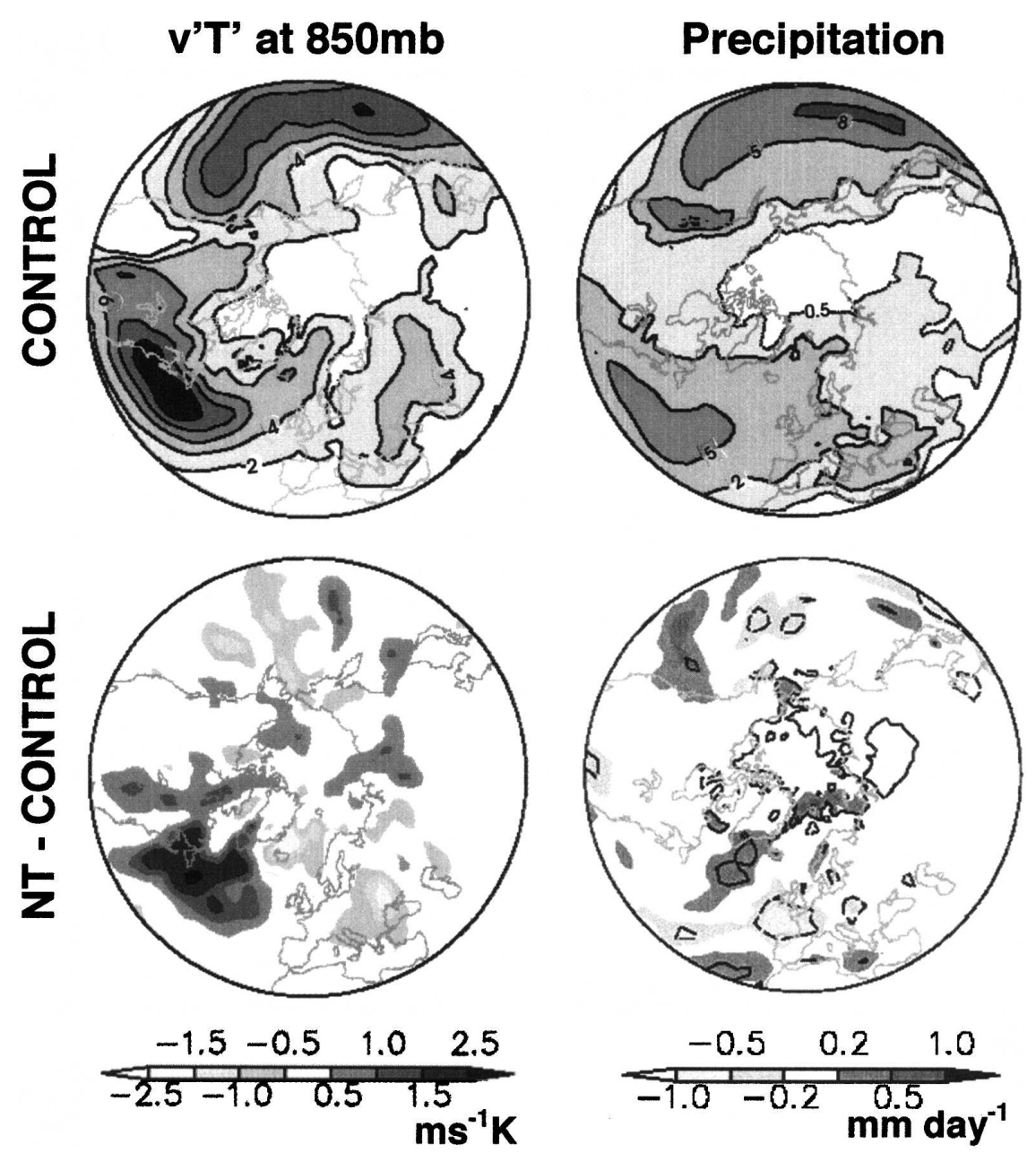

FIG. 7. Storm track activity, given as the high-pass transient poleward temperature flux at (top left) $850 \mathrm{hPa}$ and (top right) total precipitation in winter (DJF) from the CONTROL run. (bottom) Anomalies from the NT simulation are shown with contour lines to represent areas of significant differences (solid line $=$ positive anomalies, dotted line $=$ negative anomalies). The shaded keys are associated with (bottom) the anomaly plots.

the same prescribed SSTs for all simulations reduces the effect of surface incident and absorbed SW radiation on the climate. Prescribed SSTs also provide a limitless source of heat in the winter in the sense that heat loss from the ocean does not result in further cooling and formation of sea ice.

\section{c. Other fields}

\section{1) Storm Track Activity}

Storm track activity has been calculated using the high-pass transient poleward temperature flux at 850 $\mathrm{hPa}$, showing areas of maximum high-frequency variability (Fig. 7, upper-left plot). In winter three major storm tracks are simulated in the North Atlantic, North Pacific, and Southern Oceans. The northward tilt of the
North Atlantic storm track is also captured in all the models.

The NT-simulated North Pacific storm track activity is weaker in some regions than the CONTROL (Fig. 7, lower-left plot). Latitudinal temperature gradients are important for transient systems. The NT-simulated surface air temperatures (Fig. 4) were, in general, warmer over the Arctic compared to the other simulations, as described previously, due to smaller sea ice fractions allowing greater heat loss from the ocean. This weakens the overall latitudinal temperature gradient, impacting on the Pacific storm track. The low-level flow also changes (see Fig. 5) and this may also be playing a role via the barotropic governor effect (Jones 1993).

Anomalies in the North Atlantic storm track are stronger than the North Pacific track. The NT North 
Atlantic storm track is more intense at the start off the east coast of North America than the CONTROL. This suggests that changes in low-level flow patterns have a greater effect in the Atlantic sector than latitudinal temperature gradients. Specifically, increases in cyclonic circulation due to lower MSLP over the Arctic induced by negative sea ice fraction anomalies lead to enhanced westerlies and, consequently, the enhancement in the North Atlantic.

\section{2) Precipitation}

Globally, changes in precipitation are small $(<1 \%$ of global annual mean). Patterns of average winter total precipitation from the CONTROL simulation are displayed in Fig. 7 (upper-right plot). Directly over regions of discrepancy in Arctic sea ice extent at the ice edge, an increase in winter evaporation is simulated, where the sea ice fraction is lower in the NT simulation. This leads to an increase in convective and low cloud cover in these regions in winter (and autumn and spring) and an increase in precipitation. When compared to the CONTROL simulation there is a higher precipitation rate in the NT simulation around the GIN and Barents Seas, directly over regions of lower sea ice fractions (Fig. 7, lower-right plot). Storm tracks are responsible for a large proportion of midlatitude precipitation. Positive precipitation anomalies occur South of Greenland where there is an intensification of the North Atlantic storm track.

In another model experiment by Kattsov and Walsh (2000) the decrease of sea ice boundary conditions (and variation in SST and $\mathrm{CO}_{2}$ ) also produced an increase in Arctic precipitation, which was largest near the sea ice margin. The results also highlighted the need for accuracy of specified sea ice boundary conditions.

\section{North Atlantic variability}

The results described in the previous sections are concerned with the effect of sea ice specification on simulated mean climate. Of equal importance is the effect that changes in sea ice area may have on climate variability. In these simulations there is no interannual variation in sea ice boundary conditions. However, it is still possible to investigate the internal variability of the simulated system. The primary mode of variability of the Northern Hemisphere, the NAO (Hurrell 1995), was examined. The $33 \mathrm{yr}$ of monthly MSLP for the Atlantic sector $\left(20^{\circ}-80^{\circ} \mathrm{N},-90^{\circ}-90^{\circ} \mathrm{E}\right)$ were used instead as a time series for each of the four simulations. The mean annual cycle of MSLP was removed to obtain a time series of MSLP anomalies on which the empirical orthogonal function (EOF) analysis was performed.

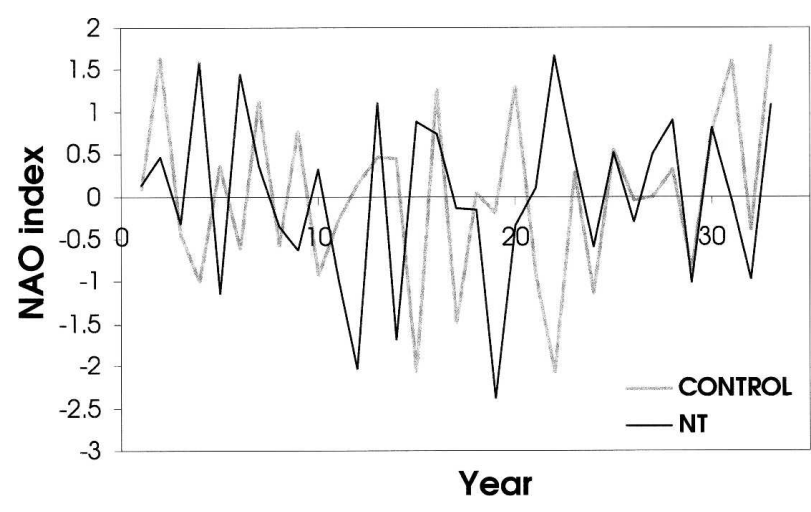

FIG. 8. Normalized index of the winter NAO calculated using EOF analysis of monthly MSLP anomalies from the CONTROL and NT experiments during 33 simulation years following the initial spinup period.

The leading EOFs of the MSLP anomaly field from the four simulations performed in this study (NT, NIC, BOOT, and CONTROL) all show similar spatial patterns as the NAO. This mode of variability accounts for $30 \%-35 \%$ of the variance of the MSLP fields. The standard deviations of the principal component time series of the leading modes (i.e., the NAO index) show that the maximum standard deviation (i.e., the time of year when the mode is most active) is in winter in all simulations, as expected. Autocorrelation analysis of each time series shows no year-to-year correlation, that is, the time series shows no interannual periodicity. The winter average NAO index derived from the NT and CONTROL experiments (Fig. 8) show no statistically significant difference in interannual variability in terms of the index variance (at the 95\% confidence level). North Atlantic wintertime climate variability is unaffected by inaccuracies in sea ice prescription and the subsequent anomalies produced in surface mean climate.

Analysis of other relevant modes of climate variability, such as the Pacific decadal oscillation, has not been undertaken because the short duration of the simulations performed here would not allow for statistically significant comparisons of oscillations with multidecadal periodicity.

\section{Conclusions}

The effect of Arctic sea ice concentration specification given by four different dataset climatologies on the simulated HadAM3 climate has been investigated. Two of the datasets were derived from PMR data only, using the NASA team and Bootstrap algorithms, which utilize different combinations of channels and different 
methods of calculating ice concentration from brightness temperature. The NIC dataset has been compiled manually from various data sources. The Met Office sea ice climatology used in conjunction with HadAM3 provided the control simulation.

Discrepancies in the sea ice datasets arise due to the different data sources and techniques used to derive ice concentration. These discrepancies are largest in the summer months, thought primarily to be due to the inability of PMR to distinguish surface meltwater areas from open water. The NIC ice-covered area in summer can be $20 \%$ greater than the NASA team PMR area. In winter, values are within $5 \%-10 \%$ in general.

The results of simulations using the four sea ice climatologies demonstrate that the smaller sea ice discrepancies in winter have the largest effect on climate. Differences in SAT were found to be over $12^{\circ} \mathrm{C}$ in some Arctic regions in winter, although the global average differences were smaller $\left(0.11^{\circ} \mathrm{C}\right)$. The coldest surface climate was obtained from the Met Office sea ice climatology (the CONTROL simulation) and the warmest from the NASA team (NT simulation). Although the NASA team sea ice extent was larger than the Met Office climatology the Met Office sea ice has higher concentrations than the NASA team. This suggests that the specification of ice extent is less critical than the areas of open water within the ice cover. Fortuitously, the climate was much less sensitive to the considerably larger uncertainties in summer sea ice specification, the time of year when ice concentration retrievals are least accurate. In winter, the large ocean-atmosphere temperature gradient (atmospheric temperatures are low in comparison with the warmer underlying ocean) and very low sea ice temperatures reached can induce large surface heat flux anomalies where sea ice discrepancies occur, leading to the high sensitivity of the winter climate to sea ice. In summer, temperature differences are much reduced, and hence the climate system is less sensitive.

In areas of reduced sea ice, as well as warming of SATs, a reduction of MSLPs over the Central Arctic was found and large increases in outgoing heat flux from the prescribed ocean in winter near the sea ice edge. There is an increase in low cloud cover in winter, and to a lesser degree in summer, over the Arctic, which is also greatest near the ice edge. An increase in winter convective cloud over the sea ice regions of discrepancies is associated with localized increased precipitation.

Examination of the potential impact on internal climate variability due to sea ice discrepancies by comparing the North Atlantic Oscillation (NAO) index produced by each of the simulations demonstrated no significant changes in interannual variability. There were more limited consequences for midlatitudes and upper troposphere, and no impact on the Tropics.

The principal implication of the study is that the prescription of sea ice concentrations requires greater accuracy in winter than in summer. Discrepancies of over $20 \%$ ice-covered area in summer have little impact on the mean climate, while $5 \%-10 \%$ differences in winter have Arctic-wide consequences for surface climate conditions. Inaccuracies in the available sea ice records (both systematic and random errors included) are large enough to significantly impact model Arctic climate biases in the lower troposphere. In terms of implications for climate change simulations, the response of the modeled climate to sea ice inaccuracies is of comparable magnitude to recent changes in Arctic climate. For example, large reductions in MSLP over the Arctic Ocean have been observed in the last few decades, which exceed $4 \mathrm{mb}$ locally (Serreze et al. 1997). Here we simulated winter Arctic MSLP anomalies of up to 5 $\mathrm{mb}$ in some regions due to sea ice inaccuracies. Consequently, equal consideration must be made for the potential errors in sea ice trends due to inaccuracies in the sea ice records. This is important given the recent decreases in mean Arctic ice thickness (Rothrock et al. 1999) and the inability of the NASA team, in particular, to correctly determine concentrations in regions of thin ice.

In this study, a high sensitivity, locally, to changes in ice concentration was demonstrated, despite the lack of SST feedbacks. The prescription of SSTs does, however, limit the full effects of sea ice changes. The prescribed ocean provides a limitless heat source in the winter, but incoming SW and LW radiation are not permitted to warm SSTs in summer to produce subsequent feedbacks on the ice pack and atmosphere, in areas of reduced sea ice. The expected increase in SSTs in summer would, however, be limited by the input of cold sea ice meltwater. In several coupled simulations (e.g., Kattenberg et al. 1996) the increase in the Arctic summer SST field in conjunction with simultaneous sea ice decreases is relatively small. The inclusion of ocean circulation may also allow propagation of temperature anomalies outside high latitudes.

It would be useful to repeat a similar experiment using the full time series of sea ice concentrations to examine the impact of different long-term linear trends and anomalous years of decreasing ice cover calculated using various observational datasets. Rinke et al. (2003) found that accurate sea ice data was required to simulate the anomalous late summer atmospheric pressure patterns of 1990. Simulations using sea ice time series 
may provide more conclusive results concerning which dataset may be more robust.

The new Advanced Microwave Scanning Radiometer (AMSR) onboard the EOS Aqua satellite, launched in 2001, will be used in conjunction with new algorithms for deriving sea ice concentrations, such as the enhanced NASA team, or NT2, algorithm. The NT2 algorithm should overcome low concentration biases while not saturating in regions of high concentration (Markus and Cavalieri 2000). The overall retrieval accuracies should improve to $\pm 4 \%$, which in the study by Parkinson et al. (2001) improved the global mean SAT range from $0.27^{\circ}$ to $0.18^{\circ} \mathrm{C}$.

Acknowledgments. This study was funded under NERC Grant NER/T/S/2001/01279 under the NERC COAPEC theme.

\section{REFERENCES}

Alexander, M. A., U. S. Bhatt, J. E. Walsh, M. S. Timlin, J. S. Miller, and J. D. Scott, 2004: The atmospheric response to realistic Arctic sea ice anomalies in an AGCM during winter. J. Climate, 17, 890-905.

Andreas, E. L, C. A. Paulson, R. M. Williams, R. W. Lindsay, and J. A. Businger, 1979: Turbulent heat-flux from Arctic leads. Bound.-Layer Meteor., 17, 57-91.

Cavalieri, D. J., P. Gloersen, and W. J. Campbell, 1984: Determination of sea ice parameters with the Nimbus 7 SMMR. $J$. Geophys. Res., 89, 5355-5369.

— , J. P. Crawford, M. R. Drinkwater, D. T. Eppler, L. D. Farmer, R. R. Jentz, and C. C. Wackerman, 1991: Aircraft active and passive microwave validations of sea-ice concentrations from the DMSP SSM/I. J. Geophys. Res., 96 (C12), 21 989-22008.

— - C. Parkinson, P. Gloersen, and H. J. Zwally, 2002: Sea Ice Concentrations from Nimbus-7 SMMR and DMSP SSM/I Passive Microwave Data. National Snow and Ice Data Center, CD-ROM.

Comiso, J. C., 1995: SSM/I ice concentrations using the Bootstrap algorithm. NASA Rep. 1380, 40 pp.

—_, 2002: Bootstrap Sea Ice Concentrations from Nimbus-7 $S M M R$ and DMSP SSM/I. National Snow and Ice Data Center, digital media.

_- 2003: Warming trends in the arctic from clear sky satellite observations. J. Climate, 16, 3498-3510.

— observations. J. Geophys. Res., 101, 28 397-28 416.

— D. Cavalieri, C. L. Parkinson, and P. Gloersen, 1997: Passive microwave algorithms for sea ice concentration: A comparison of two techniques. Remote Sens. Environ., 60 (3), 357384.

Cox, P. M., R. A. Betts, C. B. Bunton, R. L. H. Essery, P. R. Rowntree, and J. Smith, 1999: The impact of new land surface physics on the GCM simulation of climate and climate sensitivity. Climate Dyn., 15, 183-203.

Cusack, S., A. Slingo, J. M. Edwards, and M. Wild, 1998: The radiative impact of a simple aerosol climatology on the Hadley Centre climate model. Quart. J. Roy. Meteor. Soc., 124, $2517-2526$.
Deser, C., G. Magnusdottir, R. Saravanan, and A. Phillips, 2004: The effects of North Atlantic SST and sea ice anomalies on the winter circulation in CCM3. Part II: Direct and indirect components of the response. J. Climate, 17, 877-889.

Dethloff, K., C. Abegg, A. Rinke, I. Hebestadt, and V. F. Romanov, 2001: Sensitivity of Arctic climate simulations to different boundary layer parameterisations in the regional climate model. Tellus, 53A, 1-26.

Edwards, J. M., and A. Slingo, 1996: Studies with a flexible new radiation code. I: Choosing a configuration for a large-scale model. Quart. J. Roy. Meteor. Soc., 122, 689-719.

Emery, W. J., C. Fowler, and J. Maslanik, 1994: Arctic sea ice concentrations from Special Sensor Microwave Imager and Advanced Very High Resolution Radiometer satellite data. J. Geophys. Res., 99, 18 329-18 342.

Gates, W. L., and Coauthors, 1999: An overview of the results of the Atmospheric Model Intercomparison Project (AMIP I). Bull. Amer. Meteor. Soc., 80, 29-55.

Gloersen, P., W. J. Campbell, D. J. Cavalieri, J. C. Comiso, C. L. Parkinson, and H. J. Zwally, 1992: Arctic and Antarctic sea ice, 1978-1987: Satellite passive-microwave observations and analysis. NASA Special Publication 511, 290 pp.

Gregory, D., and D. Morris, 1996: The sensitivity of climate simulations to the specification of mixed phase clouds. Climate Dyn., 12, 641-651.

Gregory, J. M., P. A. Stott, D. J. Cresswell, N. A. Rayner, C. Gordon, and D. M. H. Sexton, 2002: Recent and future changes in Arctic sea ice simulated by the HadCM3 AOGCM. Geophys. Res. Lett., 29, 2175, doi:10.1029/2001GL014575.

Hollinger, J. R., R. Lo, G. Poe, R. Savage, and J. Pierce, 1991: Special Sensor Microwave/Imager Calibration/Validation. U.S. Naval Research Laboratory Final Report, Washington, D.C., 10.1-10.20.

Hoskins, B. J., and P. J. Valdes, 1990: On the existence of storm tracks. J. Atmos. Sci., 47, 1854-1864.

Hu, Z. Z., S. I. Kuzmina, L. Bengtsson, and D. M. Holland, 2004: Sea ice change and its connection with climate change in the Arctic in CMIP2 simulations. J. Geophys. Res., 109, D10106, doi:10.1029/2003JD004454.

Hurrell, J. W., 1995: Decadal trends in the North Atlantic Oscillation: Regional temperature and precipitation. Science, 269 (5224), 676-679.

Johannessen, O. M., E. V. Shalina, and M. W. Miles, 1999: Satellite evidence for an Arctic sea ice cover in transformation. Science, 286, 1937-1939.

- and Coauthors, 2004: Arctic climate change: Observed and modelled temperature and sea-ice variability. Tellus, 56A, 328-341.

Johns, T. C., R. E. Carnell, J. F. Crossley, J. M. Gregory, J. F. B. Mitchell, C. A. Senior, S. F. B. Tett, and R. A. Wood, 1997: The second Hadley Centre coupled ocean-atmosphere GCM: Model description, spinup and validation. Climate Dyn., 13 (2), 103-134

Jones, C. P., 1993: Specification of sea-ice concentration in the operational global model. Unified Model Documentation Paper 71, Met Office, United Kingdom, 5 pp.

Kattenberg, A., and Coauthors, 1996: Climate models-Projections of future climate. Climate Change 1995: The Science of Climate Change, J. T. Houghton et al., Eds., Cambridge University Press, 289-357.

Kattsov, M. K., and J. E. Walsh, 2000: Twentieth-century trends of Arctic precipitation from observational data and a climate model simulation. J. Climate, 13, 1362-1370. 
Kniskern, F. E., 1991: The Navy/NOAA Joint Ice Centers role in the climate and global change program. Global Planet. Change, 90, 207-212.

Lynch, A., W. L. Chapman, J. E. Walsh, and G. Weller, 1995: Development of a regional climate model of the Western Arctic. J. Climate, 8, 1555-1570.

Magnusdottir, G., C. Deser, and R. Saravanan, 2004: The effects of North Atlantic SST and sea ice anomalies on the winter circulation in CCM3. Part I: Main features and storm track characteristics of the response. J. Climate, 17, 857-876.

Markus, T., and D. J. Cavalieri, 2000: An enhancement of the NASA team sea ice algorithm. IEEE Trans. Geosci. Remote Sens., 38, 1387-1398.

Maykut, G. A., 1978: Energy exchange over young sea ice in the Central Arctic. J. Geophys. Res., 83, 3646-3658.

Meier, W. N., M. L. van Woert, and C. Bertoia, 2001: Evaluation of operational SSM/I ice-concentration algorithms. Ann. Glaciol., 33, 109-114.

Parker, D. E., C. K. Folland, and M. Jackson, 1995: Marine surface temperature: Observed variations and data requirements. Climate Change, 31, 559-600.

Parkinson, C. L., D. Rind, R. J. Healy, and D. G. Martinson, 2001: The impact of sea ice concentration accuracies on climate model simulations with a GISS GCM. J. Climate, 14, 26062623.

Partington, K., T. Flynn, D. Lamb, C. Bertoia, and K. Dedrick, 2003: Late twentieth century Northern Hemisphere sea-ice record from U.S. National Ice Center ice charts. J. Geophys. Res., 108, 3343, doi:10.1029/2002JC001623.

Pope, V. D., M. L. Gallani, P. R. Rowntree, and R. A. Stratton, 2000: The impact of new physical parameterisations in the Hadley Centre climate model: HadAM3. Climate Dyn., 16, 123-146.

Rinke, A., and Coauthors, 2003: A case study of the anomalous Arctic sea ice conditions during 1990: Insights from coupled and uncoupled regional climate model simulations. J. Geophys. Res., 108, 4275, doi:10.1029/2002JD003146.
Rothrock, D. A., Y. Yu, and G. A. Maykut, 1999: Thinning of the Arctic sea-ice cover. Geophys. Res. Lett., 26, 3469-3472.

Saenko, O. A., M. Eby, and A. J. Weaver, 2004: The effect of sea-ice extent in the North Atlantic on the stability of the thermohaline circulation in global warming experiments. Climate Dyn., 22, 689-699.

Serreze, M. C., F. Carse, R. G. Barry, and J. C. Rogers, 1997: Icelandic low cyclone activity: Climatological features, linkages with the NAO, and relationships with recent changes in the Northern Hemisphere circulation. J. Climate, 10, 453-464.

—, and Coauthors, 2003: A record minimum arctic sea ice extent and area in 2002. Geophys. Res. Lett., 30, 1110, doi:10.1029/2002GL016406.

Singarayer, J. S., and J. L. Bamber, 2003: EOF analysis of three records of sea-ice concentration spanning the last 30 years. Geophys. Res. Lett., 30, 1251-1254.

Smith, R. N. B., 1990: A scheme for predicting layer clouds and their water-content in a general circulation model. Quart. J. Roy. Meteor. Soc., 116, 435-460.

Steffen, K., and A. Schweiger, 1991: NASA team algorithm for sea ice concentration retrieval from Defense Meteorological Satellite Program Special Sensor Microwave Imager: Comparison with Landsat imagery. J. Geophys. Res., 96, $21971-$ 21987.

Tanis, F., and V. Smolyanitsky, Eds., 2000: Environmental Working Group Joint U.S.-Russian Arctic Sea Ice Atlas. Arctic Climatology Project, National Snow and Ice Data Center, CD-ROM. [Available from NSIDC User Services, National Snow and Ice Data Center, CIRES, 449 UCB, University of Colorado, Boulder, CO 80309-0449.]

Valdes, P. J., and B. J. Hoskins, 1989: Linear stationary wave simulations of the tie-mean climatological flow. J. Atmos. Sci., 46, 2509-2527.

Walsh, J. E., and M. S. Timlin, 2003: Northern Hemisphere sea ice simulations by global climate models. Polar Res., 22, 75-82. 